\title{
A BAC Transgenic Mouse Model to Analyze the Function of Astroglial SPARCL1 (SC1) in the Central Nervous System
}

\author{
Jill M. Weimer ${ }^{1}$, Amelia Stanco ${ }^{1}$, Jr-Gang Cheng ${ }^{1}$, Ana C. Vargo ${ }^{1}$, Santhi Voora ${ }^{1}$, and E. S. \\ Anton ${ }^{1,2, *}$ \\ ${ }^{1}$ UNC Neuroscience Center, The University of North Carolina School of Medicine, Chapel Hill, \\ North Carolina \\ ${ }^{2}$ Department of Cell and Molecular Physiology, The University of North Carolina School of \\ Medicine, Chapel Hill, North Carolina
}

\begin{abstract}
Extracellular matrix associated Sparc-like 1 (SC1/SPARCL1) can influence the function of astroglial cells in the developing and mature central nervous system (CNS). To examine SC1's significance in the CNS, we generated a BAC transgenic mouse model in which $S c 1$ is expressed in radial glia and their astrocyte derivatives using the astroglial-specific Blbp (Brain-lipid binding protein; [Feng et al., (1994) Neuron 12:895-908]) regulatory elements. Characterization of these $B l b f-S c 1$ transgenic mice show elevated $S c 1$ transcript and protein in an astroglial selective pattern throughout the CNS. This model provides a novel in vivo system for evaluating the role of $\mathrm{SC} 1$ in brain development and function, in general, and for understanding SC1's significance in the fate and function of astroglial cells, in particular.
\end{abstract}

\section{Keywords}

cerebral cortex; astroglia; SPARCL1; SC1; fatty acid binding protein 7; fabp 7

\section{INTRODUCTION}

$\mathrm{SC} 1$ is a member of the SPARC (Secreted Protein Acidic and Rich in Cysteine) family of extracellular matrix-associated proteins, which, in addition to SC1 and SPARC, includes testicans 1-3, tsc36, QR1, and SMOCs. This family of proteins is defined by the presence of a highly acidic domain I, a follistatin-like domain, and an extracellular calcium (EC) binding domain [reviewed in (Brekken and Sage, 2000; Framson and Sage, 2004; Yan and Sage, 1999)]. The follistatin-like domain, which shares homology to a repeated domain in follistatin, consists of a Kazal-type serine protease inhibitor region and an EGF domain. The EC binding domain contains a canonical pair of $\mathrm{Ca}^{2+}$ binding EF-hand motifs (Yan and Sage, 1999). The N-terminal domains of each family member exhibit the greatest divergence, and testican and tsc36/FRP both contain unique C-termini domains not present in the other members of SPARC family (Yan and Sage, 1999).

SPARC family members appear to function primarily as anti-adhesion signals. For example, $\mathrm{SC} 1 /$ hevin has been shown to inhibit attachment and spreading of endothelial cells on fibronectin in vitro (Girard and Springer, 1996). Similarly, SPARC has been shown to

*Correspondence to: E. S. Anton, UNC Neuroscience Center and the Department of Cell and Molecular Physiology, The University of North Carolina School of Medicine, Chapel Hill, NC 27599, USA. anton@ med.unc.edu. 
inhibit the formation of focal adhesion contacts by a tyrosine phosphorylation-dependant pathway, resulting in reduced adhesivity of endothelial cells in vitro (Motamed and Sage, 1998; Murphy-Ullrich et al., 1995). SPARC can also regulate cell adhesion by modulating the production and activity of matrix metalloproteinases involved in ECM remodeling (Gilles et al., 1998), by binding and sequestering $\mathrm{Ca}^{2+}$ through its $\mathrm{EC}$ domain, or through its association with ECM components such as vitronectin and collagen types I, III, IV, and V (Maurer et al., 1995; Sasaki et al., 1998). Additionally, SPARCs can function to inhibit cell cycle progression and modulate growth factor activity (Brekken and Sage, 2000, 2001; Brekken et al., 2004).

Although the SPARC family of proteins are expressed in the developing and adult CNS, their functional significance in the brain remains, for the most part, unclear (Brekken et al., 2004). Recent studies have identified that the selective expression of SC1 in radial glial strands spanning the cortical plate (CP) enables it to influence the terminal phase of neuronal migration in the developing cerebral cortex (Gongidi et al., 2004). In the adult cerebral cortex, SC1 is enriched in postsynaptic terminals and in perisynaptic glial processes surrounding the synapse (Lively et al., 2007). Following injury, reactive astrocytes rapidly upregulate SC1 (McKinnon and Margolskee, 1996; Mendis et al., 1996a; Lively et al., 2007). Although these studies suggest potentially important roles for SC1 in the development, maturation, and function of the brain, further elucidation of SC1's significance has been hampered by the lack of methods to selectively modulate SC1 expression and function in vivo in cells that mainly express it, i.e., astroglia.

Here, we describe the generation and characterization of a bacterial artificial chromosome (BAC) transgenic mouse line that expresses $S c 1$ under the transcriptional control of the Brain lipid-binding protein (Blbp or fatty acid binding protein 7, Fabp7) regulatory elements (Feng et al., 1994; Xu et al., 1996). This promoter region has been well characterized and used successfully to drive gene expression selectively in radial glia and their astrocytic progeny from embryonic day 13 onwards in the developing CNS (Anthony et al., 2004, 2005; Feng and Heintz, 1995). Utilization of the BAC transgenic approach allows for selective expression of $\mathrm{SC} 1$ in $\mathrm{BLBP}^{+}$astroglial cells under more stable conditions than traditional transgenic approaches (Heintz, 2001). Widespread expression of SC1 was achieved in astroglial cells of the cerebral cortex, hippocampus, midbrain, and cerebellum in these mice. Generation of these mice provides a novel tool for the analysis of the role of $\mathrm{SC} 1$ in distinct compartments of the developing and adult mammalian brain.

\section{METHODS}

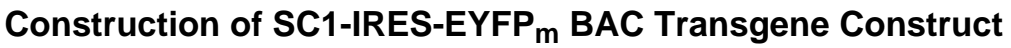

$S C I-I R E S-E Y F P_{m}-p A$ was cloned into pCMV-Zeo (Invitrogen, V50120). CMV-Zeo was then replaced with floxed Neo cassette from p452 (a gift from Dr. N. Copeland of NCI) to introduce Neo as a selection marker for recombineering and to provide additional unique sites of restriction endonuclease to ligate with homologous arms for targeting. The $S C 1$ $I R E S$ - $E Y F P_{m}-p A$ was then inserted into Blbp exon 1 within C57 mouse BAC (RP23-81N21). With the deletion of 160 bp of exon 1 and part of intron 1, this transgene starts transcription after 39nt from the Blbp transcription initiation site (Fig. 1A).

\section{Generation of BAC Transgenic Mice}

Purified BAC was used for pronuclear microinjection of fertilized eggs from the CBA X C57B16 mouse strain at the UNC Animal Model core facility. Fertilized ovum was subsequently implanted into pseudo-pregnant females and offspring were analyzed for the insertion of the BAC construct. Founder lines were identified by Southern blot analysis of 
tail DNA (Fig. 1C). An [a- $\left.{ }^{32} \mathrm{P}\right]$ dCTP labeled DNA probe was generated from an $857 \mathrm{bp}$ NheI-BsrGI fragment of the $\mathrm{pEYFP}_{\mathrm{m}}$ plasmid and used to probe the DNA blot. Independent breeding lines were established from four of the founders (named Blbp-Sc1 $1^{1-4}$ ) and subsequent offspring were analyzed by PCR, using the following primers, $5^{\prime}$ CCA AGA CCA GGT ACC ATG $3^{\prime}$ and $5^{\prime}$ GCC AGG GTT TTC CCA GT $3^{\prime}$, complimentary to exon 2 of the Blbp BAC (RP23-81N21) and EYFP, respectively. Blbp-Sc1 ${ }^{1-4}$ lines were maintained on a C57B16 background and all animals were housed under identical conditions. All procedures were carried out in accordance with NIH guidelines and The University of North Carolina's Animal Care and Use Committee Guidelines.

\section{In Situ Hybridization}

$S c 1$ probe spans sequence \#902-1832 of the mouse $S c 1$ cDNA sequence. The $S c 1$ in situ construct was generated by RT-PCR from mouse brain cDNAs using $S c 1$ specific primers (5' GGC TGA AGA AAG CCA GAC AC $3^{\prime}$ and 5' CTG CAG TTG GTG TCC CTT TT $\left.3^{\prime}\right)$ and the $930 \mathrm{bp}$ amplified product was cloned into pBluescript SK(+). After linearization with EcoRV, antisense transcripts were produced using T7 RNA polymerase. In situ hybridization on brain sections from Blbp-Sc1 transgenic and wildtype control mice was performed as previously described (Anton et al., 2004) at the UNC Neuroscience Center's in situ hybridization core facility. All images were captured under identical conditions using an Axio-Cam camera attached to a Zeiss Axioplan 2 microscope. The relative levels and spatial distribution of transgene expression was determined by reviewing multiple sections from different $B l b p-S c 1$ transgenic lines and by comparison to sense control labeled slides.

\section{Quantitative Real-Time-PCR}

To assess the relative expression levels of $S c 1$ in the $B l b p-S c 1$ transgenic lines, RNA was extracted from $B l b p-S c 1$ transgenic or wildtype cortex and cerebellum using Trizol (Invitrogen). High fidelity cDNA was generated from each RNA sample (SuperScript II, Invitrogen). QRT-PCR reaction samples were prepared as a mixture containing Sybergreen POWER Universal Master Mix ${ }^{\mathrm{TM}}$ (Synthegen), forward and reverse primers for $S c 1$ or Gapdh, and equal amounts of cDNAs. The following primers were used: Gapdh, $5^{\prime}$ TGTGTCCGTCGTGGATCTGA-3' and 5'-CCTGCTTCACCACCTTCTTGA-3'; Sc1, $5^{\prime}$ GGCTGAAGAAAGCCAGACAC- $3^{\prime}$ and $5^{\prime}$-GTGTCCTTCTGGTTGCCAAT- $3^{\prime}$.

Reactions were performed using an Applied Biosystems Prism 9700 PCR machine. Relative expression of $S c 1$ levels $(S c 1 / G a p d h)$ in wildtype and $B l b p-S c 1$ samples was determined as described by Pfaffl 2001.

\section{Immunohistochemistry and Immunoblotting}

Wildtype and $B l b p-S c 1$ brains were harvested and processed for immunohistochemistry or immunoblotting as described earlier (Gongidi et al., 2004; Schmid et al., 2003). Briefly, brain tissue was either fixed in $4 \%$ paraformaldehyde for immunohistochemistry or flash frozen for Western blot analysis. Fixed brains were sagittally sectioned (30 $\mu \mathrm{m}$ thick) and processed for immunolabeling with a rat anti-SC1 antibody [11-59, generous gift of Dr. E. Helene Sage, The Hope Heart Institute]. Immunoreactivity was detected with Cy2 conjugated, anti-rat secondary antibodies (Jackson Immunoresearch). For Western blot analysis, harvested brains were homogenized in lysis buffer [20 mM Tris, pH 7.4, $150 \mathrm{mM}$ $\mathrm{NaCl}, 10 \%$ Glycerol, $1 \%$ NP40, $0.25 \%$ Deoxycholate, $0.1 \%$ SDS, and protease inhibitors (Sigma)]. Equal amounts of proteins were then separated on 4-20\% gradient SDS-PAGE gels and immunoblotted with anti-SC1 antibodies as described in Gongidi et al., 2004. 


\section{RESULTS}

\section{Generation of SC1-IRES-EYFP $m$ BAC Transgenic Mouse Model}

To test $\mathrm{SC} 1$ functions in the developing and mature brain, we have generated a BAC transgenic mouse model where SC1/SPARCL1 is expressed specifically in radial glial cells and their astrocyte derivatives using the astroglial specific Blbp (Brain lipid-binding protein or fatty acid binding protein 7, Fabp7) regulatory elements. Disrupted normal $S c 1$ expression in the developing and mature astroglial cells in these Blbp-Sc1 transgenic mice provides a framework to evaluate the role of astroglial SC1 in the brain. Previous studies have shown that the Blbp regulatory elements can drive gene expression in an astroglialspecific manner starting around embryonic day 13 (Anthony et al., 2004, 2005; Feng and Heintz, 1995). A SCI-IRES-EYFP $P_{m}-p A$ construct containing $S c 1$, separated from the enhanced, membrane targeted yellow fluorescent protein $\left(E Y F P_{m}\right)$ by an internal ribosomal entry signal (IRES), was generated and cloned into pCMV-Zeo (Invitrogen, V50120). CMV-Zeo was then replaced with floxed Neo cassette from p452 (a gift from Dr. N. Copeland of NCI) to introduce Neo as a selection marker for recombineering and to provide additional unique sites of restriction endonuclease to ligate with homologous arms for targeting. The Sc1-IRES-EYFP m- A was then inserted into Blbp exon 1 within C57 mouse BAC (RP23-81N21). With the deletion of $160 \mathrm{bp}$ of exon 1 and part of intron 1, the transgene starts after 39 nt from the Blbp transcription initiation site (Fig. 1A). Prior to generation of BAC-transgenic mice, Blbp-Sc1 plasmids were electroporated into the ventricles of embryonic day 15 mice to ensure that transgene expression in the developing cerebral cortex was restricted to radial glial cells (Schmid et al., 2006).

The purified BAC construct was used for pronuclear microinjection of fertilized eggs from C57B16 strain mice at UNC Animal Models core facility. Six founder lines were identified by Southern blot analysis of tail DNA using a probe for the Blbp-Sc1 transgene (Fig. 1B). Independent breeding lines were established from four of these lines (named $B l b p-S c 1^{1-4}$ ). Expression of this transgene does not appear to affect the overall viability of transgene positive progeny.

\section{Characterization of Blbp-Sc1 Transgene Expression}

We initially performed in situ hybridization to examine the $S c 1$ expression pattern in the CNS of $B l b p-S c 1$ transgenic lines and control wildtype mice. Compared to wildtype cerebral cortex, elevated $S c 1$ expression is evident throughout the cortex (Fig. 2B and C). Although there was a marked elevation in expression in all regions of the cerebral cortex, the most striking rise in $S c 1$ expression was seen in the region of occipital and parietal cortex. In the hippocampus, widespread increase in astroglial $S c 1$ expression was noticed, especially in the regions of the subiculum, CA3, and dentate gyrus (Fig. 2D and E). In the striatum, stellate shaped, multipolar astroglial cells prominently expressed $S c 1$ (Fig. 2F and G). Furthermore, significant upregulation of $S c 1$ in Bergmann glia of the cerebellum was also evident in these transgenic lines (Fig. $2 \mathrm{H}-\mathrm{K}$ ). Labeling with $S c 1$ sense control probes showed no detectable signal (data not shown).

To further demonstrate that introduction of the $B l b p-S c 1$ transgene resulted in an upregulation of $S c 1$ expression within the CNS of these transgenic lines, we performed quantitative RT-PCR (QRT-PCR) analysis of $S c 1$ expression in the cortex and cerebellum of $B l b p-S c 1$ mice using $S c 1$ specific primers. These findings reveal a significant increase in the level of $S c 1$ transcript in the cerebral cortex and cerebellum of Blbp-Sc1 transgenic mice when compared to wildtype controls (Fig. 2L).

To determine whether the upregulation of $S c 1$ mRNA in the $B 1 b p-S c 1$ transgenic mice corresponds to an increase in $\mathrm{SC} 1$ protein expression, we performed immunoblot analysis of 
whole cell extracts from $B l b p-S c 1$ cerebral cortex. Increase levels of the $116 \mathrm{kDa} S \mathrm{SC} 1$ protein was noticed in Blbp-Sc1 cortices (Fig. 3E). Moreover, immunolabeling of sections of cerebral cortex and cerebellum with anti-SC1 antibodies indicates increased levels of SC1 in both the cerebral cortex as well as the cerebellum of Blbp-Sc1 transgenic mice (Fig. 3). $\mathrm{SC} 1$ expression is apparent in astroglial cells throughout the cortex (Fig. 3A and B). In cerebellum, Bergmann glial cells and their processes selectively express enhanced levels of SC1 (Fig. 3C and D). Taken together, these in situ hybridization observations, QRT-PCR analysis, immunoblotting, and immunohistochemical evaluation of $B l b p-S c 1$ transgenic mice demonstrate that $\mathrm{SC} 1$ is over-expressed in an astroglial-specific manner in these mice and thus, they provide an in vivo model to examine the significance of astroglial restricted $\mathrm{SC} 1$ expression and function in the CNS.

\section{DISCUSSION}

Generation and characterization of a BAC transgenic mouse model in which astroglial selective over-expression of $\mathrm{SC} 1$ is achieved will facilitate the analysis of $\mathrm{SC} 1$ functions, particularly those mediated through astroglia, in the development and maturation of distinct brain structures. Considering the known functional redundancy of SPARC family of proteins in the brain and the entailing difficulties in using traditional knock-out approach to delineate functional significance of SPARC family members (Gilmour et al., 1998; McKinnon et al., 2000; Roll et al., 2006), this approach provides a useful model to analyze SC1 function in a cell type specific manner in the brain.

SC1's expression in the developing, mature, and injured brain suggests that it may influence multiple cellular processes during distinct stages of brain development and function. In the embryonic brain, $\mathrm{SC} 1$ is prominently expressed in radial glia where it functions to terminate radial glial guided neuronal migration by reducing the adhesivity of neurons to the radial glial scaffold (Gongidi et al., 2004). Furthermore, SC1 is also expressed in the proliferative ventricular zone (VZ) of the embryonic cortex where it may influence the dynamics of radial glial cell proliferation and survival (Girard and Springer, 1995, 1996; Gongidi et al., 2004). Additionally, the presence of anti-adhesive signals such as SC1 in the VZ may play a role in turning VZ directed subpopulation of neurons back on a trajectory towards the $\mathrm{CP}$ (Nadarajah et al., 2002; Yokota et al., 2007). The selective SC1 expression in the VZ and $\mathrm{CP}$, and the differential function of $\mathrm{SC} 1$ in distinct cerebral wall domains could, in turn, provide a mechanism for the coordination of neural precursor proliferation and neuronal placement in the developing neocortex. SC1 is also expressed in Bergmann glia of the developing cerebellum, where selective transport of SC1 may influence glial guided migration or modulation of synaptic activity (Brekken et al., 2004; Mothe and Brown, 2000). In the mature brain, SC1 expression persists in radial glial derivatives, that is, astrocytes. SC1 expression in astrocytes adjacent to synapses is hypothesized to modulate synaptic function (Lively et al., 2007). These varied functions of SC1 that are mediated through radial glia or astrocytes could be further evaluated using $B l b p-S c 1$ transgenic lines where normal expression of SC1 is selectively disrupted in these cells.

Following brain injury, $\mathrm{SC} 1$ is rapidly upregulated in reactive astrocytes around the site of injury (Lively and Brown, 2007; McKinnon and Margolskee, 1996; Mendis et al., 1996a,b). This upregulation in astrocytes may enhance the repair process following injury and the $B l b p-S c 1$ transgenic mouse model could help to evaluate this possibility. Although the exact levels of SC1 upregulation necessary to induce repair mechanism follow focal trauma has not been established, the Blbp-Sc1 transgenic mouse model induces an over 30-fold induction of $S c 1$ mRNA expression in the adult cerebral cortex and over 5-fold induction in the cerebellum. Furthermore, SC1 may also be involved in the pathogenesis of multiple neural traumas. For example, proteomic analysis of cerebrospinal fluid from multiple 
sclerosis patients showed an upregulation of SC1 expression (Scalabrini et al., 2007). SC1 may also function as a tumor suppressor and is aberrantly expressed in brain tumors (Framson and Sage, 2004; Sullivan and Sage, 2004). SC1's ability to remodel extracellular matrix, regulate cell cycle progression, and act as substrate for apoptosis regulators, such as caspase-3, may be highly relevant to its function in these aberrantly proliferating and invasive brain tumor cells (Hambrock et al., 2003; Ju et al., 2007; Sullivan et al., 2006). $B l b p-S c 1$ transgenic lines could be crossed with various mouse brain tumor models (Uziel et al., 2005; Xiao et al., 2002; Zurawel et al., 2000) to evaluate if enhanced astroglial SC1 expression could modulate the formation and progression of gliomas.

In summary, $\mathrm{SC} 1$ expression in the astroglial cells of the developing, mature, and injured brain is highly suggestive of dynamic functions of this protein in the CNS. The generation of a $B l b p-S c 1$ transgenic mouse model described here provides a useful system for determining in vivo how astroglial expression of $\mathrm{SC} 1$ contributes to the construction and function of distinct brain regions.

\section{Acknowledgments}

The authors thank Eleanor Saunders for technical assistance.

Grant sponsor: NIH; Grant number: MH060929; Grant sponsor: NRSA; Grant number: NS056686; Grant sponsor: NINDS-funded Center.

\section{REFERENCES}

Anthony TE, Klein C, Fishell G, Heintz N. Radial glia serve as neuronal progenitors in all regions of the central nervous system. Neuron. 2004; 41:881-890. [PubMed: 15046721]

Anthony TE, Mason HA, Gridley T, Fishell G, Heintz N. Brain lipid-binding protein is a direct target of Notch signaling in radial glial cells. Genes Dev. 2005; 19:1028-1033. [PubMed: 15879553]

Anton ES, Ghashghaei HT, Weber JL, McCann C, Fischer TM, Cheung ID, Gassmann M, Messing A, Klein R, Schwab MH, Lloyd KC, Lai C. Receptor tyrosine kinase ErbB4 modulates neuroblast migration and placement in the adult forebrain. Nat Neurosci. 2004; 7:1319-1328. [PubMed: 15543145]

Brekken RA, Sage EH. SPARC, a matricellular protein: At the crossroads of cell-matrix communication. Matrix Biol. 2001; 19:816-827. [PubMed: 11223341]

Brekken RA, Sullivan MM, Workman G, Bradshaw AD, Carbon J, Siadak A, Murri C, Framson PE, Sage EH. Expression and characterization of murine hevin (SC1), a member of the SPARC family of matricellular proteins. J Histochem Cytochem. 2004; 52:735-748. [PubMed: 15150282]

Feng L, Hatten ME, Heintz N. Brain lipid-binding protein (BLBP): A novel signaling system in the developing mammalian CNS. Neuron. 1994; 12:895-908. [PubMed: 8161459]

Feng L, Heintz N. Differentiating neurons activate transcription of the brain lipid-binding protein gene in radial glia through a novel regulatory element. Development. 1995; 121:1719-1730. [PubMed: 7600988]

Framson PE, Sage EH. SPARC and tumor growth: Where the seed meets the soil? J Cell Biochem. 2004; 92:679-690. [PubMed: 15211566]

Gilles C, Bassuk JA, Pulyaeva H, Sage EH, Foidart JM, Thompson EW. SPARC/osteonectin induces matrix metalloproteinase 2 activation in human breast cancer cell lines. Cancer Res. 1998; 58:55295536. [PubMed: 9850090]

Gilmour DT, Lyon GJ, Carlton MB, Sanes JR, Cunningham JM, Anderson JR, Hogan BL, Evans MJ, Colledge WH. Mice deficient for the secreted glycoprotein SPARC/osteonectin/BM40 develop normally but show severe age-onset cataract formation and disruption of the lens. Embo J. 1998; 17:1860-1870. [PubMed: 9524110]

Girard JP, Springer TA. High endothelial venules (HEVs): Specialized endothelium for lymphocyte migration. Immunol Today. 1995; 16:449-457. [PubMed: 7546210] 
Girard JP, Springer TA. Modulation of endothelial cell adhesion by hevin, an acidic protein associated with high endothelial venules. J Biol Chem. 1996; 271:4511-4517. [PubMed: 8626806]

Gongidi V, Ring C, Moody M, Brekken R, Sage EH, Rakic P, Anton ES. SPARC-like 1 regulates the terminal phase of radial glia-guided migration in the cerebral cortex. Neuron. 2004; 41:57-69. [PubMed: 14715135]

Hambrock HO, Nitsche DP, Hansen U, Bruckner P, Paulsson M, Maurer P, Hartmann U. SC1/hevin. An extracellular calcium-modulated protein that binds collagen I. J Biol Chem. 2003; 278:1135111358. [PubMed: 12538579]

Heintz N. BAC to the future: The use of bac transgenic mice for neuroscience research. Nat Rev Neurosci. 2001; 2:861-870. [PubMed: 11733793]

Ju W, Valencia CA, Pang H, Ke Y, Gao W, Dong B, Liu R. Proteome- wide identification of family member-specific natural substrate repertoire of caspases. Proc Natl Acad Sci USA. 2007; 104:14294-14299. [PubMed: 17728405]

Lively S, Brown IR. Analysis of the extracellular matrix protein SC1 during reactive gliosis in the rat lithium-pilocarpine seizure model. Brain Res. 2007; 1163:1-9. [PubMed: 17628511]

Lively S, Ringuette MJ, Brown IR. Localization of the extracellular matrix protein SC1 to synapses in the adult rat brain. Neurochem Res. 2007; 32:65-71. [PubMed: 17151913]

Maurer P, Hohenadl C, Hohenester E, Gohring W, Timpl R, Engel J. The C-terminal portion of BM-40 (SPARC/osteonectin) is an autonomously folding and crystallisable domain that binds calcium and collagen IV. J Mol Biol. 1995; 253:347-357. [PubMed: 7563094]

McKinnon PJ, Margolskee RF. SC1: A marker for astrocytes in the adult rodent brain is upregulated during reactive astrocytosis. Brain Res. 1996; 709:27-36. [PubMed: 8869553]

McKinnon PJ, McLaughlin SK, Kapsetaki M, Margolskee RF. Extracellular matrix-associated protein Sc1 is not essential for mouse development. Mol Cell Biol. 2000; 20:656-660. [PubMed: 10611244]

Mendis DB, Ivy GO, Brown IR. Sc1, a brain extracellular matrix glycoprotein related to SPARC and follistatin, is expressed by rat cerebellar astrocytes following injury and during development. Brain Res. 1996a; 730:95-106. [PubMed: 8883893]

Mendis DB, Shahin S, Gurd JW, Brown IR. SC1, a SPARC-related glycoprotein, exhibits features of an ECM component in the developing and adult brain. Brain Res. 1996b; 713:53-63. [PubMed: 8724975]

Motamed K, Sage EH. SPARC inhibits endothelial cell adhesion but not proliferation through a tyrosine phosphorylation-dependent pathway. J Cell Biochem. 1998; 70:543-552. [PubMed: 9712151]

Mothe AJ, Brown IR. Selective transport of SC1 mRNA, encoding a putative extracellular matrix glycoprotein, during postnatal development of the rat cerebellum and retina. Brain Res Mol Brain Res. 2000; 76:73-84. [PubMed: 10719217]

Murphy-Ullrich JE, Lane TF, Pallero MA, Sage EH. SPARC mediates focal adhesion disassembly in endothelial cells through a follistatin-like region and the $\mathrm{Ca}(2+)$-binding EF-hand. J Cell Biochem. 1995; 57:341-350. [PubMed: 7539008]

Nadarajah B, Alifragis P, Wong RO, Parnavelas JG. Ventricle-directed migration in the developing cerebral cortex. Nat Neurosci. 2002; 5:218-224. [PubMed: 11850632]

Pfaffl MW. A new mathematical model for relative quantification in real-time RT-PCR. Nucleic Acids Res. 2001; 29:e45. [PubMed: 11328886]

Roll S, Seul J, Paulsson M, Hartmann U. Testican-1 is dispensable for mouse development. Matrix Biol. 2006; 25:373-381. [PubMed: 16806869]

Sasaki T, Hohenester E, Gohring W, Timpl R. Crystal structure and mapping by site-directed mutagenesis of the collagen-binding epitope of an activated form of BM-40/SPARC/osteonectin. Embo J. 1998; 17:1625-1634. [PubMed: 9501084]

Scalabrini D, Fenoglio C, Scarpini E, De Riz M, Comi C, Venturelli E, Cortini F, Piola M, Villa C, Naldi P, Monaco F, Bresolin N, Galimberti D. Candidate gene analysis of SPARCL1 gene in patients with multiple sclerosis. Neurosci Lett. 2007; 425:173-176. [PubMed: 17825989]

Schmid RS, McGrath B, Berechid BE, Boyles B, Marchionni M, Sestan N, Anton ES. Neuregulin 1erbB2 signaling is required for the establishment of radial glia and their transformation into 
astrocytes in cerebral cortex. Proc Natl Acad Sci USA. 2003; 100:4251-4256. [PubMed: 12649319]

Schmid RS, Yokota Y, Anton ES. Generation and characterization of brain lipid-binding protein promoter-based transgenic mouse models for the study of radial glia. Glia. 2006; 53:345-351. [PubMed: 16288463]

Sullivan MM, Sage EH. Hevin/SC1, a matricellular glycoprotein and potential tumor-suppressor of the SPARC/BM-40/Osteonectin family. Int J Biochem Cell Biol. 2004; 36:991-996. [PubMed: 15094114]

Sullivan MM, Barker TH, Funk SE, Karchin A, Seo NS, Hook M, Sanders J, Starcher B, Wight TN, Puolakkainen P, Sage EH. Matricellular hevin regulates decorin production and collagen assembly. J Biol Chem. 2006; 281:27621-27632. [PubMed: 16844696]

Uziel T, Zindy F, Xie S, Lee Y, Forget A, Magdaleno S, Rehg JE, Calabrese C, Solecki D, Eberhart CG, Sherr SE, Plimmer S, Clifford SC, Hatten ME, McKinnon PJ, Gilbertson RJ, Curran T, Sherr CJ, Roussel MF. The tumor suppressors Ink4c and p53 collaborate independently with Patched to suppress medulloblastoma formation. Genes Dev. 2005; 19:2656-2667. [PubMed: 16260494]

Xiao A, Wu H, Pandolfi PP, Louis DN, Van Dyke T. Astrocyte inactivation of the pRb pathway predisposes mice to malignant astrocytoma development that is accelerated by PTEN mutation. Cancer Cell. 2002; 1:157-168. [PubMed: 12086874]

Xu LZ, Sanchex R, Sali A, Heintz N. Ligand specificity of brain lipid-binding protein. J Biol Chem. 1996; 271:24711-24719. [PubMed: 8798739]

Yan Q, Sage EH. SPARC, a matricellular glycoprotein with important biological functions. J Histochem Cytochem. 1999; 47:1495-1506. [PubMed: 10567433]

Yokota Y, Gashghaei HT, Han C, Watson H, Campbell KJ, Anton ES. Radial glial dependent and independent dynamics of interneuronal migration in the developing cerebral cortex. PLoS ONE. 2007; 2:e794. [PubMed: 17726524]

Zurawel RH, Allen C, Wechsler-Reya R, Scott MP, Raffel C. Evidence that haploinsufficiency of Ptch leads to medulloblastoma in mice. Genes Chromosomes Cancer. 2000; 28:77-81. [PubMed: 10738305] 


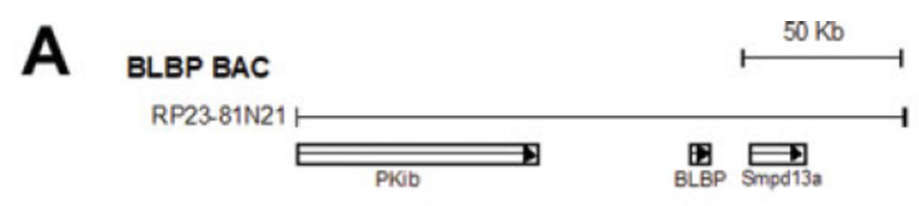

B
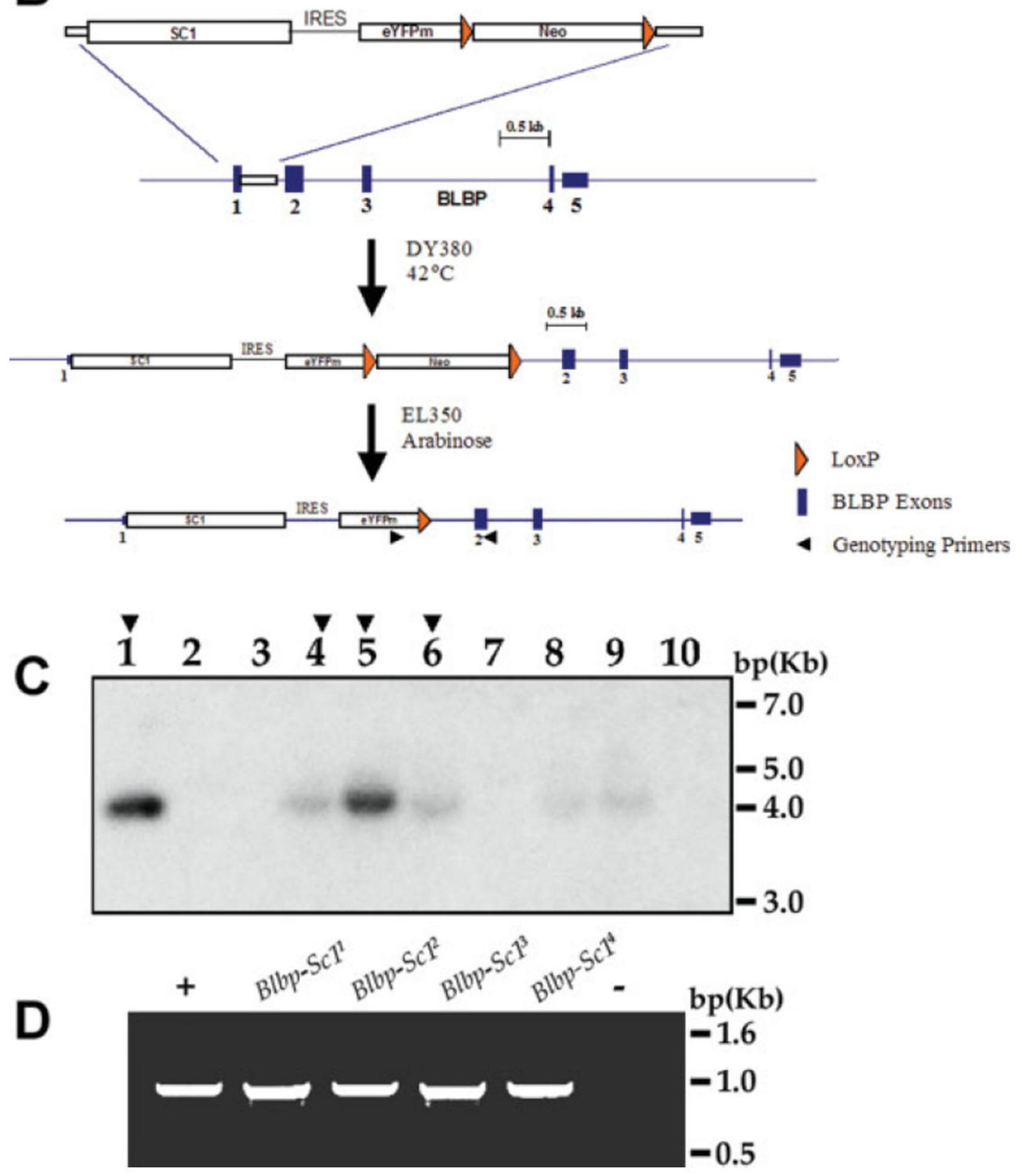

Fig. 1.

Generation of Blbp promoter- SC1-IRES-EYP $m$ mice. (A) BLBP BAC clone (RP23-81N21), indicating the location of Blbp and nearby genes, Pkib and Smapdl3a. (B) Insertion of transgene (SCI-IRES-EYFP ${ }_{m-p A}$ ) into Blbp BAC clone. Integration of the transgene by homologous recombination, followed by selection of the targeted BAC clone, and removal of the Neo- cassette. BLBP-SCI-IRES-EYFP ${ }_{m}-p A$ transgene thus generated was used to drive astroglial specific expression of $S c 1$ in the developing and mature brain. (C) Six founder lines were identified by Southern blot analysis of tail DNA and independent breeding lines were established from four (named $B l b p-S c 1^{1-4}$ ). (D) A single PCR product 
of 950-bp size was detected with primers complementary to Blbp-BAC and EYFP from $B I b p-S c 1^{1-4}$ DNA. The transgene plasmid was used as a positive control (+ lane) and DNA isolated from wildtype mice (- lane) was used as a negative control. [Color figure can be viewed in the online issue, which is available at www.interscience.wiley.com.] 

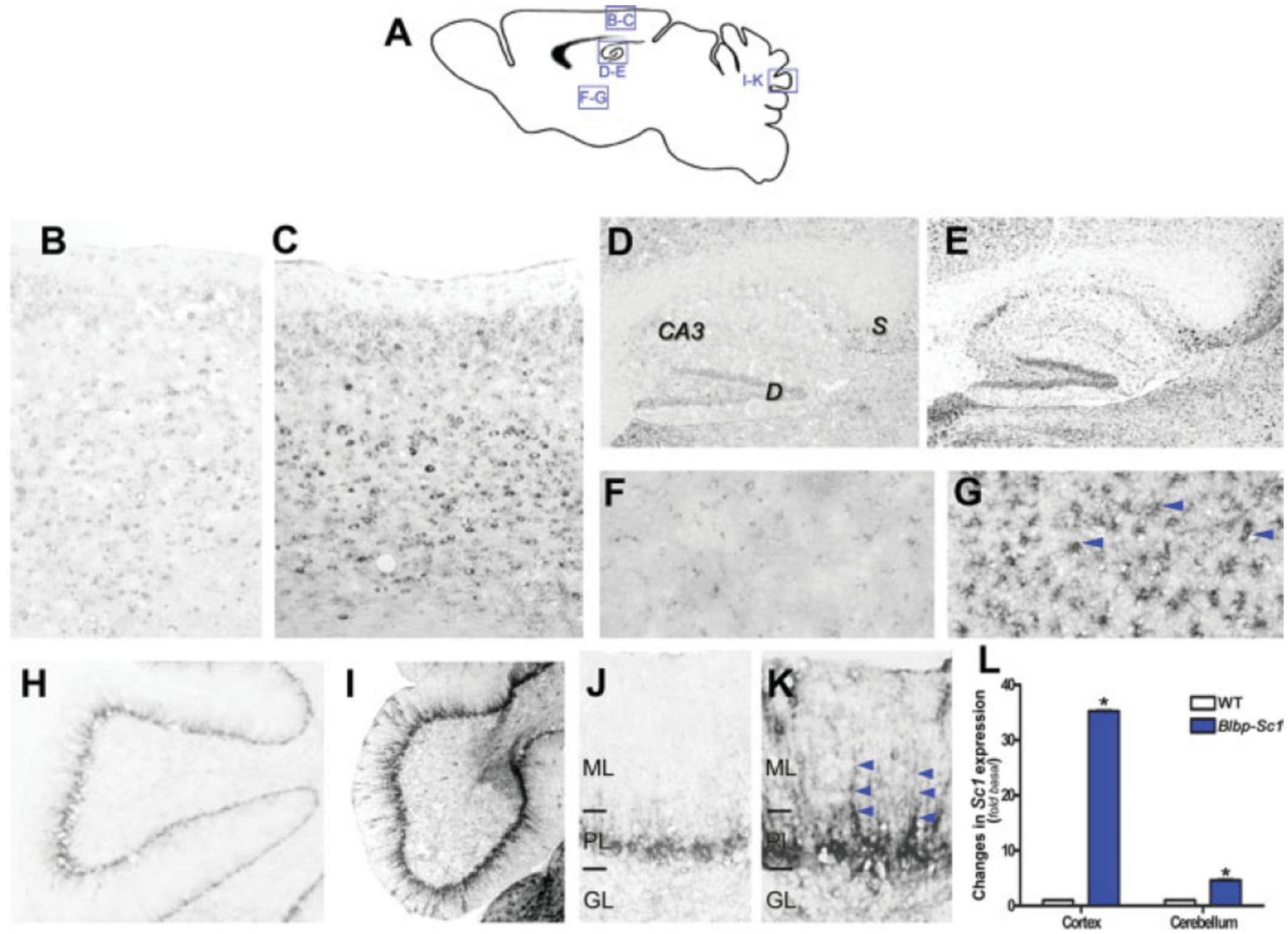

Fig. 2.

Patterns of $S c 1$ expression in $B l b p-S c 1$ transgenic mice. In situ hybridization analysis demonstrated elevated expression of $S c 1$ transcript in distinct regions of the CNS of Blbp$S c 1$ transgenic mice. $S c 1$ expression in $B l b p-S c 1$ transgenic mice $(\mathbf{C}, \mathbf{E}, \mathbf{G}, \mathbf{I}, \mathbf{K})$ was compared with age-matched controls $(\mathbf{B}, \mathbf{D}, \mathbf{F}, \mathbf{H}, \mathbf{J})$. Regions examined are indicated on a schematic of the sagittal view of adult brain (A) $S c 1$ expression is upregulated in cerebral cortex (B, C); hippocampus (D, E); striatum (F, G); cerebellum (H-K). Arrowheads (G) indicate $S c 1$ overexpressing multipolar astrocytes in the striatum. Higher magnification images of the cerebellum indicates prominent $S c 1$ overexpression in Bergmann glia with elongated processes in Blbp-SC1 mice (arrowheads, K). Quantitative RT-PCR analysis with $S c 1$ specific primers reveals a significant increase in the level of $S c 1$ transcript in both the cerebral cortex and cerebellum of Blbp-Sc1 transgenic mice compared to wildtype controls (L). Data shown are mean \pm SD. Asterisks indicates significance compared with controls at $P<0.001$ (Student's $t$ test). S, subiculum; DG, dentate gyrus; ML, molecular layer; PL, Purkinje layer; GL, granule layer. [Color figure can be viewed in the online issue, which is available at www.interscience.wiley.com.] 

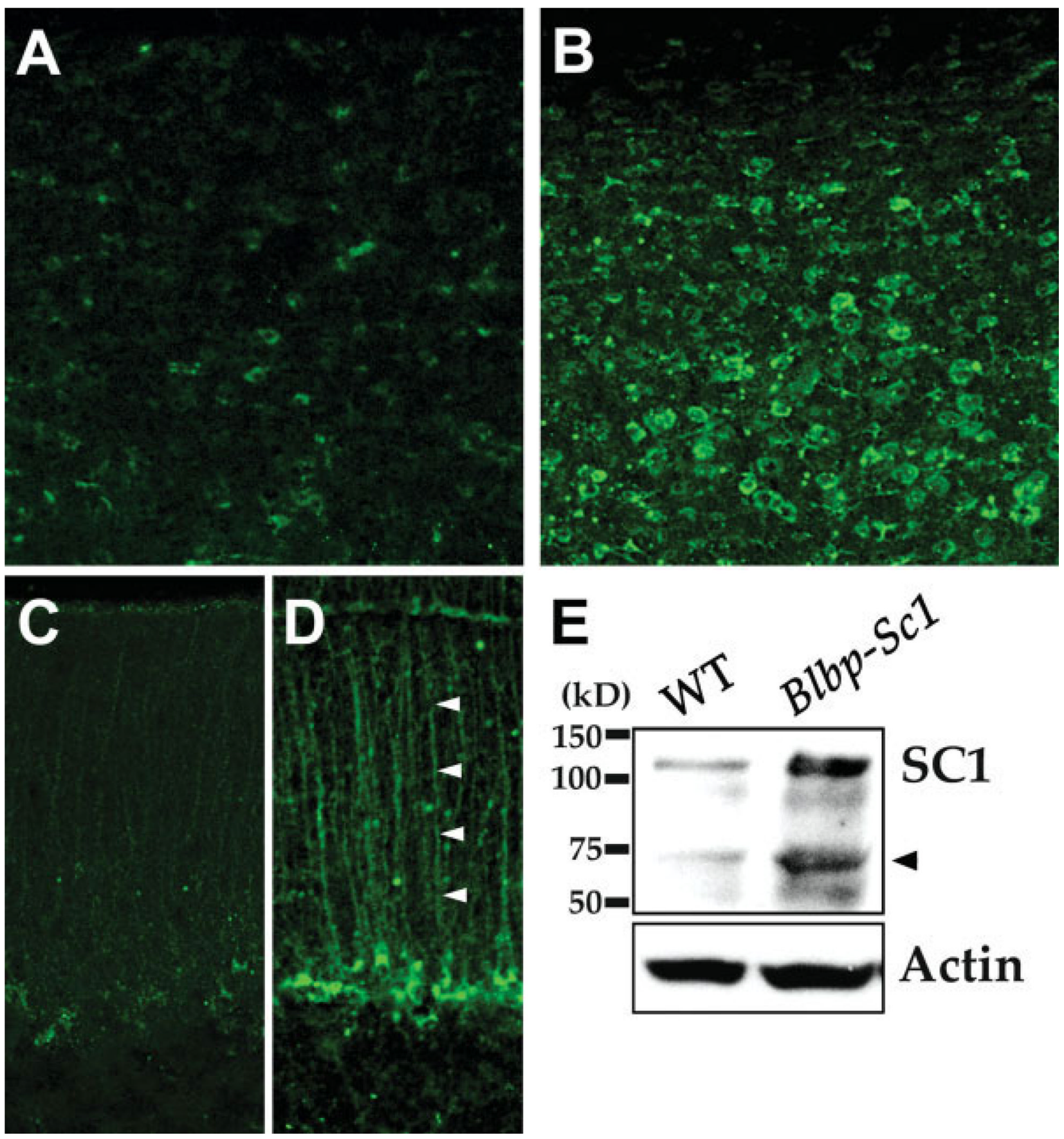

Fig. 3.

Elevated expression of $\mathrm{SC} 1$ in the cerebral cortex and cerebellum of $B \mathrm{lbp}-\mathrm{Sc} 1$ transgenic mice sections of adult cortex and cerebellum were immunolabeled with anti-SC1 antibodies. Increased levels of $\mathrm{SC} 1$ are seen in astroglial cells of $B l b p-S c 1$ transgenic mice within both the cortex (B) and the cerebellum (D), as compared to basal levels of SC1 expression in wildtype mice (A [cortex], C [cerebellum]). Arrowheads (D) indicate Bergmann glia of the cerebellum. Immunoblot analysis of Blbp-Sc1 brains demonstrates an increase in the levels of the $116 \mathrm{kDa} \mathrm{SC1}$ protein $(\mathbf{E})$. Arrowhead (E) indicates the unprocessed precursor of SC1. 
[Color figure can be viewed in the online issue, which is available at www.interscience.wiley.com.] 